\title{
Thoughts on the Ageing Body
}

\author{
Francesca Ghillani ${ }^{1}$
}

Received: 12 January 2021 / Accepted: 7 July 2021 / Published online: 14 August 2021

(c) The Author(s) 2021

\begin{abstract}
Recent studies have taken into account the fact that the lives of older people have changed drastically in the past fifty years. Older people today engage more with society and are also expected to maintain an active role in their communities. In order to maintain a positive social status, todays older adults need both to challenge negative stereotypes and also to achieve the "unachievable" positive representations in the media. Society plays a complex game of bodily images: the artificial image of the human body in the media, the image that individuals try to project, and the image that society reflects back to the individual. When the three don't coincide, the collision creates a distancing effect. To truly understand the lived experiences of older adults in contemporary society we must explore the changing perceptions of the body. This review will illustrate the arguments both classical and contemporary through an exploration of the ageing female body, which remains the focus of most of the literature.
\end{abstract}

Keywords Ageing · Body · Women

\section{Thinking the Body in Society}

The body has not always been an important field of study in social sciences. Nevertheless, in recent decades the interest in the topic has progressively grown. In 1978, "The Civilizing Process", written by Norbert Elias in 1939, was translated into English. In his work, Elias recognized the need to contextualize bodily practices in their historical context. The author examined the evolution of good manners in Europe from the middle ages to the present, concluding that the growth of civilization has been achieved as a result of a collective effort to control emotions and the consequent shift in social expectations (Elias, 1978). Elias also argued that bodies are not isolated but are all connected and interdependent (ibid.).

Francesca Ghillani

francesca.ghillani@ageing.ox.ac.uk

1 Oxford Institute of Population Ageing, University of Oxford, 66 Banbury Road,

Oxford OX2 6PR, UK 
In "Techniques of the Body", Mauss (1973) argued that although when babies are born they use their bodies following their instinct, adults have no natural way to manage their bodies. He explains that each society develops particular techniques for the use of the body that are acquired from youth and permeate the individual to the core of the self. The norms that regulate the use of the body are communal and are transmitted by learning and imitation. Mauss takes into consideration very basic movements that are experienced daily, such as walking: the way human beings put one foot in front of the other is the result of the cultural selection of one particular type of walk amongst unlimited possibilities (Mauss, 1979).

Around the same time, Michel Foucault highlighted the link between the body, knowledge, and power. In "Discipline and Punish" and "The History of Sexuality" he draws a distinction between two types of power that are used over the body: the first, sovereign power, is held by the state in the form of laws; the second, disciplinary power, is a form of micro-control applied by public surveillance. Later, Foucault also identified biopower, or the power over health, illnesses, and all primary bodily functions (Foucault, 1977, 1979). The consequence of all forms of power on the body is the emergence of bodily practices, which Foucault called "technologies", aimed at training, confining, and shaping the body, and making it "docile" to power. For example, clothing is a form of discipline of the body that limits its expression in a realm of possibilities considered socially acceptable.

In contrast, Maurice Marleu-Ponty argued that the body is not only an object but is an experience lived every day by the individual. He used the word "embodiment" to indicate a circular relationship between the body, the observer, and the observed, where perception plays a predominant role and where the body generates meanings and practices. In his discourse on the phenomenology of the body, Marleu-Ponty also uses the classical categories of space and time to describe how the body can be lived differently in different contexts (Merleau-Ponty, 1962).

Along the same lines, Bordieu recognized that the work of structuralist thinkers, such as Foucault, lacked the concept of agency. Rejecting the idea of subjectivism that sees human actions as arising from an unconscious self, the author uses a concept of practice that is described as being adaptive to the context but also strategic for change. This concept, named "habitus", is the action that stems from the dialogue between the present and the internalized dispositions acquired during childhood through socialization. Habitus is neither a habit nor a numb repetition, Bourdieu stresses, but is a dynamic concept, a disposition that interacts with the existing contingencies to create new contents (Bourdieu, 1984).

In 1984, Bryan Turner was the first to introduce the term"somatic society", in which the body is the location of the problematization and expression of personal and political problems. Turner argued that the images of bodies had become prominent in society due to the use of human figures in the media, especially advertising (Turner, 1984). Along the same lines, Featherston (1982) analysed the obsession of consumerism with the body, arguing that individuals in contemporary society are compelled to develop performance skills in order to master their public image and live up to their narcissistic expectations.

Consumer culture has indeed shaped most of what a body is expected to be today. John Berger has uncovered how vision is central to defining the place occupied by 
an individual in society in his work "Ways of Seeing", a four-part television series that later became a book (Berger et al., 1973). Here he considers images of women's bodies, from classic art to modern commercial advertising. What is interesting to note here is the acknowledgement that women have been the subject of social scrutiny for centuries and increasingly since technology has allowed the manipulation of images of the body. Similarly, in his essay "The Emperor's New Clothes", Marshall McLuhan looks at the rapidly growing phenomenon of commercial advertising and defines it as a "magical environment" (McLuhan, 1968), stressing the importance of the technological revolution that at the time was allowing a profound transformation in the way the media portrayed human bodies.

On the same topic, a sense of disorientation is expressed by philosopher Giorgio Agamben. In "The Coming Community", he discusses the female body and its usage in commercial marketing and consumerism. Recalling an advertisement for stockings shown in Italian cinemas during the 1970s, Agamben investigates the concept of happiness in relation to the body. Since the process of commercialization started investing in the human figure, he argues, the body has been both subjected to norms and released from its utility as functional object. In fact, the figure of the body in advertising has been manipulated with technology, creating a dissonance with reality.

In recent years, social scientists have tried to rethink the body according to the growing importance of its representation in the media. Drawing upon the difference established by Barthes between the work, as a material object, and the text, as a methodological field existing only in a discourse and defined only as activity and production, Csordas delineated a distinction between the body and the textuality of the body. These two aspects are complementary and not mutually exclusive (Csordas, 1993). The notion of "somatic modes of attention" (ibid.) brings together perceptual consciousness and collective practice, reinforcing the idea that the way an individual attends the world to and with the body is influenced by society. Similarly, Donna Haraway has pinpointed the difference between the body as a "social actant", which refers to the mere materiality of the body, and the body as a "social agent", which indicates this materiality as an ineluctable element in the practices of selfexpression (Haraway, 1997).

The term 'beauty work' (Clarke \& Griffin, 2007) emphasizes that the final purpose of all practices aimed at modifying the body and its appearance is the adherence to a specific concept of beauty. In the game of the social gaze, every individual is at the same time active and passive; observer and observed. Every person imposes her judgement on other's social performance. At the same time, every person is the focus of a verdict imposed by others. This situation is made even more complicated by the fact that norms are not homogenous and are often ambivalent.

Today, the literature about the body in society is mostly focused on very specific aspects and, in most cases, it lacks a real discussion about the historical basis of the field. One recent approach, defined "wardrobe studies", is a development on the classical topic of clothing and its importance as a symbolic method of presenting the self. In addition, this approach brings a new light on the importance of the materiality of garments and how they form complicated interactions as part of a wardrobe (Klepp \& Bjerck, 2014). 
Although many authors have stressed the dangers of focusing on the medical aspects about the body, the recent developments in medicine and biotechnologies have produced a significant amount of literature. New methods of fertility, biology, genetic manipulation human enhancement achieved thanks to biotechnologies, are only a few disciplines that have contributed to this discourse. A recent field of study has emerged, being labelled "posthumanism" (Sharon, 2014). New categories are being defined by scholars of different fields, and they all stem from new concepts of what it means to be a human being. In this field, the body plays a central role, as the most pressing question seems to be how the contemporary body is transformed by modernity and how this affects the relationship between nature and society (ibid.).

\section{The Body and Social Interaction}

The body and its appearance carry the first signs that regulate the social interaction between two individuals. Individuals recognize each other as members of a certain community when they perform and share the same practices. The concept of socialization is defined in the life-course perspective as "a process of committing an individual to term of service in a group, by progressively confining his behavioural potentialities within an acceptable range and by preparing him for the types of role he will be expected to play" (Ryder, 1965). In other words, every society instils rules of behaviour to members of its society and the internalization of the moral and social codes builds social identity and makes an individual a part of that community. In this sense, socialization becomes a social act when an individual lives inside a community and abides by its social rules. The process of socialization is accomplished by society through several agents, such as school, family, peer group, the media, religion, etc. from childhood, and continues throughout the entire life course. In other words, individual's identities, their behaviour, and how they make sense of the world are constructed historically and culturally by society (Pilcher, 1994).

The way individuals use and perceive their body is heavily influenced by such socialization. Shilling defines the socialization of the body as "involving the hiding away of natural functions and the transformation of bodies into a location for and an expression of codes of behaviour" (Shilling, 2012). He also argues that the body is increasingly social and that its natural functions are hidden with the help of technologies and objects-such as razors, make-up, toiletries. The body in contemporary western societies is defined by Shilling as a "civilized body", to underline that it is controlled and invested with new meanings through a process of rationalization that is progressively becoming more entangled with the social, cultural, and physical location of the individual. As we described earlier, Elias has showed how the process of rationalizing the body is historically embedded (Elias, 1978). It is interesting to note that the body and related practices respond to social needs of the cultural environment. Moreover, socialization is deeply rooted in its historical context. Individuals change their beliefs and attitudes in response to major social movements or events. According to Mannheim, experiences are not accumulated in the course of a lifetime through a process of summation or agglomeration; they are dialectically articulated. In any case, Mannheim suggests that the experiences 
acquired in youth are predominant and will always play a role in what we learn later (Mannheim, 1936).

It is also interesting to note that understanding socialization in old age requires the acknowledgement of both the positive and negative changes that occur in later life, as well as the recognition of the accumulated knowledge from previous experiences. Fingerman and Pitzer have analysed the importance of agents of socialization in later life, such as past and present relationships, and culture. The latter is controversial, as the authors see culture as less relevant in later life than in previous ages but they focus on a vision of ageing as centred on tradition and disability (Fingerman \& Pitzer, 2007). However, they see that culture can affect ageing and may cause low self-esteem as an agent of socialization when the representations and stereotypes of older people are negative. In their work, the authors acknowledge that further research is needed in to understand the influence of social milieu on older people's behaviours, beliefs, and emotions (ibid.).

\section{The Body and Ageing}

Although the discourse about the body is about all social classes and crosses the divides of gender, race, and sexual identity, the category of age has long been neglected and has come to the forefront of social discourse only in recent years.

Twigg has noted that "biomedical accounts occupy a privileged and dominant position" in how the ageing body is understood in social sciences (Twigg, 2004). On a similar note, Small argued that predominance of medical discourse about ageing is dangerous because the negative attitudes towards old age are more difficult to shift when they are related to mental and bodily decline (Small, 2007). The difficulty is augmented by the fact that these developments have taken place in the context of a consumer culture, where the body has become a site of self-identity and reflexivity (Twigg, 2004). This paragraph will focus on the idea that the concept "old" is constantly pervaded by a sense of otherness that can be damaging for those who enter or are already in what we call "later life", as older people try to distance themselves from this category fearing marginalization.

In their effort to redefine embodiment as a framework that "encompasses all those actions performed by the body or on the body which are inextricably oriented towards the social" (Gilleard \& Higgs, 2015), Gilleard and Higgs have also discussed the relationship between corporeality and society. The authors' predominant focus on ageing and the way it is performed allows them to underline that all the actions of the body towards society must be considered in their personal and historical context. In fact, they emphasize the need to end the thought of ageing as a universal experience with an intrinsic value and univocal development. In their work, Gilleard and Higgs also argue that embodied practices are not only used as a form of expression but can also ignore or mask certain traits of an individual's identity. The ageing body itself has been considered a mask for a younger-or even agelessself, an idea launched by Featherstone and Hepworth that has since become a central motif in the discourse about ageing and the body (Featherstone \& Hepworth, 1991). When the emphasis is stressed on the bodily aspects of ageing, inevitably the world 
"old" assumes a negative meaning. Moreover, when the ageing body starts showing signs of decay, it cannot escape the label "old", therefore it becomes a source of negative stereotypes about ageing: old age is entirely perceived as a loss. Indeed, the body links the self to others in ways the individuals are only partially aware of: they are perceived via the body, and they perceive the world through the body. Thus, it can be argued that the body is the surface on which the self and culture meet.

As Small has pointed out, for every conventional stereotype of "old age" "there's an equally recognizable counter-association" (Small, 2007). For instance, it is interesting to note that the word "old" does not have a fixed meaning, but it is used with different meanings in different contexts. In fact, in institutional settings, such as health services, it can become a positive feature, when it allows access to special services (Paoletti, 1998). Old age is obviously a period of life loaded with expectancy, promises, and mystery. It is almost impossible to consider it as just one period of our life. In "States of Injury", Wendy Brown describes what she calls "the plastic cage", a series of definitions made by others that imprisons weaker individuals in definite roles (Brown, 1995). It is impossible to escape from this prison, because even refusing social definitions reinforces them. Hagestad underlines the importance of the "awareness of old age as part of a long life journey, of individual lives as embedded in a changing social context" (Hagestad 2001). Looking ahead to the future, the individual feels the need to find a sense of continuity and of "sameness" across life; "making sense" means that, looking ahead, we have some basic predictability (Hagestad, 1986).

\section{Women, Ageing, and the Body}

In 1949, Simone De Beauvoir was the first to bring gender to the forefront of the sociological and philosophical discourse, analysing the situation of women in western culture and highlighting the idea that women are considered "the other" (Beauvoir, 1997). Indeed, most of the classical and contemporary literature on ageing and the body refers to female bodies. Male bodies and trans bodies have to date only received limited attention. We shall thus focus on women as our illustration of ageing and the body.

The literature about how women distance themselves from the word "old" is constantly growing. In particular, Hurd's work on the notion of ageing suggests that women as old as 90 negotiate the meaning of age in order to maintain membership of the category "not old" (Hurd, 1999). The process seems to be circular: women refuse to refer to themselves as old both because negative values are attached to the social image of old people and because they see positive aspects of their lives as discordant with their idea of life as an elderly person. In other words, since later life is categorized as negative, when a woman lives a fulfilling life she will not be able to recognize it as the life of an older person. This process is influenced by and influences stereotypes and contributes to the conceptualization of oldness as "other".

In recent years, Grosz has revisited the notion of "docile bodies" introduced by Foucault, calling women's bodies "volatile", a term that challenges the Cartesian divide between mind and body with the notion that the two cannot be separated. 
The author rejects the "somatophobic" idea that women should be considered only for their inner world, and calls for a corporeal feminism to be added to the discourse about the differences between men and women (Grosz, 1994).

Nevertheless, in the field of studies about women and the body, biomedical accounts occupy a privileged and dominant position, especially when the focus is on ageing; still, even if the centrality of the body is unquestionable, it is important to recognize that the body is socially constructed (Twigg, 2004), therefore, examining the body under the lens of culture is crucial. How do women represent, experience, and reflect on the body? What are their everyday perceptions and beliefs about body and ageing? And what role does society play in these dynamics?

As Twigg has noted, "old remains eternally other" (Twigg, 2004). There is a discontinuity in women's contemporary identity, which is emphasised in the discourse about the body. The body represents the "here and now" of the individual in society. It is possible to "re-member" (give a new body to) memories of past selves and, therefore, to incorporate personal memory to the present self, but it is not possible to escape the present body (Marzano Parisoli, 1999). As a result, changes in the body can be a source of discontinuity, creating a moment of fracture in the continuity of life. Moreover, the way the body changes is, at least in part, out of our control. On the one hand, there are experiences such as menarche and menopause, which are considered leaps in a completely different corporal and social identity, rather than smooth transitions in a constant flow, making the life course less steady. On the other hand, pregnancy is described as a change of the body that happens at the same time as the transition into a new realm of social identity, as the pregnant body translates on the outside the unequivocal transition of the self to the new social role of mother. In her study, Bailey found that a change in identity was experienced by pregnant women partly because of the new way they conceptualized their bodies (Bailey, 1999).

Ruble and Brooks-Gunn call "adjustment" the process of transforming the self to prepare it for a new bodily and social status (ibid.). A similar word, "adapting," is used in disability studies to indicate the process of "altering life and self to accommodate to bodily losses and to reunify body and self accordingly" (Charmaz, 1995). Gerontologists use the term "reminescence" to designate "how older adults socially construct the meaning of their lives" looking at the past (Covan, 2005); however, the process of looking ahead and trying to predict the future, called "preminescence" is equally important for the construction and adaptation of older women's identity (ibid.). This is illustrated by Ruble and Brooks-Gunn, in their 1982 study, highlighted the importance of preparedness in young girls coping with menarche. They found that girls who were not well prepared to face the onset of menstruation reported negative initial reactions and more symptoms (Ruble \& Brooks-Gunn, 1982). Interestingly, they also found that being unprepared had a negative impact on the girls' self-image.

If the beginning of the fertile period seems to be problematic, its end does not seem any easier. Although nowadays there are more women living a long life after menopause, becoming older is still difficult for many of them. The media advertises anti-ageing products and tell women that looking younger is an obligation; moreover, feminine bodies face functional changes, and an augmented sense of frailty and 
weakness. Menopause is a moment of permanent transition from the role of potential mother to that of potential grandmother. Facing these important bodily changes (menarche, pregnancy, and menopause) is more complicated for migrants, who are still not fully able to understand the social norms of their country of destination and are, at the same time, unable to fully understand how to prepare for these changes, as the two cultures can be significantly different. For instance, in her study about the menopause in North America and Japan, Lock highlights a significant difference between how the two societies understand menopause. The Japanese use two words to indicate menopause: the word "hekei", which refers to the end of menstruation, and the word "konenki", which describes a life passage, and can be related to men as well. Interestingly, the two concepts are not related and one doesn't imply the other. The author explains that "unlike 'menopause', which in western medical discourse increasingly indexes a highly focused physiological complex, 'konenki' is a polysemic term covering a multitude of signs, symptoms and embodied processes" (Lock, 1993).

\section{The Role of Contemporary Imaging}

A new representation of an ageing woman has become popular in the media in the past few decades, especially in women's magazines; it is one of an attractive and confident mid-life woman. As Ussher has stated, "the new message is "Life begins at 40" (or even at 50)" (Ussher, 2006). The older woman can be depicted as a reassuring yet sporty grandmother, a good-looking but modest wife, a sober and conscious fashion victim. If in the 1950s a woman, after marriage, could just wear an apron and cut her hair short, now she has a new, demanding model challenging her. It is only the last of the clichés a woman will find in her life but this one comes suddenly, almost unexpectedly, in peculiar continuity with the previously learnt feminine features. The constant message that women receive from the media is that looking younger is desirable and can be obtained with discipline (Coupland, 2009). Consequently, looking younger is an obligation for social acceptance and failing to hide one's age leads to stigma, as it signals the inability of the individual to follow social norms. Such contradictions have serious consequences: age is deprived of its qualitative meaning and the onset of a new standards exposes women to ferocious comparisons. As a consequence, when reaching midlife, a woman's self can become dysfunctional when feeling detached from the changing body. Anti-ageing products are sold as a solution to the problem (Coupland, 2009), supporting the idea that age in years and age in appearance do not have to match and thus deepen the confusion about what "old" means.

An extensive body of literature indicates that women do not abandon concerns about their appearance as they age (Armstrong et al., 2009). Twigg argues, the link between clothing, identity, and the self remains strong during the entire life course. For this reason, clothing choices are an important site of study of the ways in which the body and the self interrelate with the social and cultural expectations (Twigg, 2009). Clothing choices are deemed appropriate or inappropriate for a member of the community according to these norms, and a great part of social identity is 
expressed with appropriate choices that can demonstrate the capability of being a functional and valuable member of the society. There is evidence that clothing evolves, especially in women, throughout the entire life course, reflecting the relationship between individual perceptions, bodily changes, and norms that are socially and culturally constructed and shared. The changes in women's clothing choices sometimes reflect changes that happen to their bodies. At other times, changes are imposed by the social context and are related to the image that the woman wants to project of herself as a member of the community. These are the changes that can inform how society understands the concept of oldness.

It is clear that in social science, ageing has often been represented as a mere bodily process, with a focus on medical issues, as if the experience of ageing wasn't mediated by culture and society. Recently, the focus has shifted and there is more consciousness about the idea that the society in which individuals grow up determines the way they experience and practise their bodies throughout their life course, including old age (Twigg \& Martin, 2015). Linking the micro and macro analysis levels, the Life-Course perspective encompasses the social dynamics linked to the process of ageing that take place at both levels (Bengtson et al., 1997), therefore, it is an important framework to understand how ageing is created by "social contexts, cultural meanings, and social structural location" (ibid.).

Acknowledgements I am extremely grateful to Prof. Sarah Harper CBE, Oxford Institute of Population Ageing, for her invaluable advice and support

Open Access This article is licensed under a Creative Commons Attribution 4.0 International License, which permits use, sharing, adaptation, distribution and reproduction in any medium or format, as long as you give appropriate credit to the original author(s) and the source, provide a link to the Creative Commons licence, and indicate if changes were made. The images or other third party material in this article are included in the article's Creative Commons licence, unless indicated otherwise in a credit line to the material. If material is not included in the article's Creative Commons licence and your intended use is not permitted by statutory regulation or exceeds the permitted use, you will need to obtain permission directly from the copyright holder. To view a copy of this licence, visit http://creativecommons.org/licen ses/by/4.0/.

\section{References}

Armstrong, M. L., Saunders, J. C., \& Roberts, A. E. (2009). Older women and cosmetic tattooing experiences. Journal of Women \& Aging, 21(3), 186-197.

Bailey, L. (1999). Refracted selves? A study of changes in self-identity in the transition to motherhood. Sociology, 33(2), 335-352.

Bengtson, V. L., Burgess, E. O., \& Parrott, T. M. (1997). Theory, explanation, and a third generation of theoretical development in social gerontology. The Journals of Gerontology Series B: Psychological Sciences and Social Sciences, 52(2), S72-S88.

Bourdieu, P. (1984). Distinction: A social critique of the judgement of taste. Routledge.

Brown, W. (1995). States of injury: Power and freedom in late modernity. Princeton University Press.

Charmaz, K. (1995). The body, identity, and self: Adapting to impairment. The Sociological Quarterly, 36(4), 657-680.

Clarke, L. H., \& Griffin, M. (2007). The body natural and the body unnatural: Beauty work and aging. Journal of Aging Studies, 21(3), 187-201.

Coupland, J. (2009). Discourse, identity and change in mid-to-late life interdisciplinary perspectives on language and ageing. Ageing \& Society, 29(6), 849-861. 
Covan, E. K. (2005). Meaning of aging in women's lives. Journal of Women \& Aging, 17(3), 3-22.

Csordas, T. J. (1993). Somatic modes of attention. Cultural Anthropology, 8(2), 135-156.

Elias, N. (1978). The civilizing process: The history of manners. Urizen Books.

Featherstone, M. (1982). The body in consumer culture. Theory, Culture \& Society, 1(2), 18-33.

Featherstone, M., \& Hepworth, M. (1991). The mask of ageing and the postmodern life course. The body: Social process and cultural theory (pp. 371-389). Sage.

Fingerman, K. L., \& Pitzer, L. (2007). Socialization in old age. Handbook of socialization: Theory and research (pp. 232-255). Guilford Press.

Foucault, M. (1977). Discipline and punish: The birth of the prison. Allen Lane.

Foucault, M. (1979). The history of sexuality. Allen Lane.

Gilleard, C., \& Higgs, P. (2015). Aging, embodiment, and the somatic turn. Age Culture Humanities, 2, 17-33.

Grosz, E. A. (1994). Volatile bodies: Toward a corporeal feminism. Allen \& Unwin.

Hagestad, G. (1986). Dimensions of time and the family. American Behavioral Scientist, 29(6), 679-694.

Hagestad, G., \& Dannefer, D. (2001). Concepts and theories of aging. In Handbook of Aging and the Social Sciences. Academic.

Haraway, D. J. (1997). Modest_Witness@Second_Millennium.FemaleMan_Meets_OncoMouse:Feminism and Technoscience. Routledge.

Hurd, L. C. (1999) “WE'RE NOT OLD!”: Older women's negotiation of aging and oldness. Journal of Aging Studies, 13(4), 419-419.

Klepp, I. G., \& Bjerck, M. (2014). A methodological approach to the materiality of clothing: Wardrobe studies. International Journal of Social Research Methodology, 17(4), 373-386.

Lock, M. M. (1993). Encounters with aging: Mythologies of menopause in Japan and North America. University of California Press.

Mannheim, K. (1936). Ideology and Utopia: An introduction to the sociology of knowledge. Routledge \& Kegan Paul.

Martin, E. (1988). Premenstrual syndrome: Discipline, work, and anger in late industrial societies. In T. Buckley \& A. Gottlieb (Eds.), Blood magic: The anthropology of menstruation (pp. 161-181). University of California Press.

Marzano Parisoli, M. M. (1999). Fino a quando e fino a che punto io resto me stesso? Corpo, integrità e identità personale. [Until when and to which point do I remain myself? Body, Integrity and Personal Identity]. Idee, 40, 223-243.

Mauss, M. (1973). Techniques of the body. Economy and Society, 2(1), 70-88.

Mauss, M. (1979). Sociology and psychology: Essays. Routledge \& Kegan Paul.

McLuhan, M. (1968). The Emperor's New Clothes. In M. Mcluhan (Ed.), Through the vanishing point: Space in poetry and painting (pp. 237-261). Harper \& Row.

Merleau-Ponty, M. (1962). Phenomenology of perception. Routledge \& Kegan Paul.

Paoletti, I. (1998). Being an older woman: A study in the social production of identity. Lawrence Erlbaum Associates.

Pilcher, J. (1994). Mannheim's sociology of generations: An undervalued legacy. British Journal of Sociology, 45(3), 481-495.

Ruble, D. N., \& Brooks-Gunn, J. (1982). The experience of Menarche. Child development. Early Adolescence, 53(6), 1557-1566.

Ryder, N. B. (1965). The Cohort as a concept in the study of social change. American Sociological Review, 30(6), 843-861.

Sharon, T. (2014). Human nature in an age of biotechnology: The case for mediated posthumanism (Philosophy of engineering and technology; 14). Dordrecht.

Small, H. (2007). The long life. Oxford University Press.

Turner, B. S. (1984). The body and society: Explorations in social theory. Basil Blackwell.

Twigg, J. (2009). Dress and the narration of life: Women's reflection on clothing and age. In Sparkes. A. C. (ed) Auto/Biography Yearbook, BSA Auto/Biography Study Group. Russell Press,1-18.

Twigg, J. (2004). The body, gender, and age: Feminist insights in social gerontology. Journal of Aging Studies, 18(1), 59-73.

Twigg, J., \& Martin, W. (2015). Routledge handbook of cultural gerontology. Routledge.

Ussher, J. M. (2006). Managing the monstrous feminine: Regulating the reproductive body. Routledge. 
Publisher's Note Springer Nature remains neutral with regard to jurisdictional claims in published maps and institutional affiliations. 